\title{
Insecticidal Effect of Bacillus thuringiensis var Kurstaki on the Various Instars Larvae of Plutellax ylostella L. (Lep.: plutellidae) Under Laboratory Condition
}

\author{
Shaban Ranjbari ${ }^{1}$, Mohammad Hassan Safaralizadeh ${ }^{2}$, Shahram Aramideh ${ }^{3}$ \\ 1- MSe Student, Department of Plant Protection, University of Urmia, Iran. \\ 2- Professor, Department of Plant Protection, University of Urmia, Iran \\ 3- PHD, Department of Plant Protection, University of Urmia, Iran \\ Corresponding author: Ahar88_1305@yahoo.com,
}

\begin{abstract}
Due to economic importance of diamondback moth pest and resistance to conventional insecticides, it is necessary to use novel and suitable compounds in control programs. Therefore, we evaluated the toxicity of Bacillus thuringiensis to four instars larvae of diamondback moth, Plutella xylostella (L.). In this study 1st, 2nd, 3rd and 4th instars larvae were exposed to different concentrations of Bacillus thuringiensis. The exposure times were 24, 48 and $72 \mathrm{~h}$ for oral trials. Experiments were performed in complete randomized block design with four replications. After treatment the samples were held under constant conditions in laboratory rearing room $\left(25 \pm 2^{\circ} \mathrm{C}, 50 \pm 5 \% \mathrm{RH}\right.$ and 14 and 10 hrs. L: D photoperiod). The maximum mortality rate for 1st, 2nd, 3rd and 4th instars larvae in 90, 140, 200 and 250 ppm of Bacillus thuringiensis was achieved 98.33, 97.67, 96.67 and 90\% after 72 h, respectively. Our results suggest Bacillus thuringiensis could be an important agent in control of larval instars of Plutella xylostella.
\end{abstract}

Key words: Bacillus thuringiensis, Bioassay, cabbage, Plutella xylostella

\section{INTRODUCTION}

The diamondback moth, Plutella xylostella L. (Lepidoptera: plutellidae) is the most destructive insect pest of cruciferous crops throughout the world (Talekar and Shelton, 1993).The pest was controlled easily with insecticides until 1980 when severe failures of pesticides began to occur and progressively grocers reported resistance problems (Dunhawoor et al., 1998). New insecticides are continuously being developed as existing insecticides become useless, but Plutella xylostella has developed resistance very quickly to many of these ( Nisin, et al. 2000); (Shelton, et al. 2000). Microbial insecticides are a promising alternative, the most widely used microbial insecticide. Bacillus thuringiensis Berliner, is highly toxic to certain pests, yet it has little or no adverse effect on most non target organisms, including humans (Flexner et al. 1986); (Wilcox, et al. 1986).

Bacillus thuringiensis is a rodshaped, gram-positive, soil bacterium that produces crystalline inclusions during sporulation. Bacillus thuringiensis is not a single entity, but a highly diverse one with about 50 serotypes that are further subdivided into 63 serovars based on H-flagellar antigen technique (Thiery and Frachon, 1997). Bacillus thuringiensis is especially useful for control of diamondback moth, a worldwide pest of cruciferous vegetables. Bacillus thuringiensis does not harm the hymenopterous parasitoids of diamondback moth (Brunner and Stevens, 1986), but it is highly effective against diamondback moth that are resistant to conventional insecticides (Sun, et al. 1986). The objective of the 
present study was to investigate the different doses effects of Bacillus thuringiensis on the various instars larvae of $P$. xylostella under laboratory conditions and determination of concentration at which maximum mortality occur.

\section{MATERIALS AND METHODS Insects}

Plutella xylostella larvae and pupae were collected from cabbage (Brassica oleracea var. capitata) in an experimental field of the college of Natural Resource and Environment, during February 2010 in the Urmia area (Iran) agricultural university. Pest were reared in a colony of 2-3 generations in an automatic climate apparatus at (25 \pm 2$)$ ${ }^{\circ} \mathrm{C}$, under a 14: $10 \mathrm{~L}$ : D photoperiod, and fed on cabbage seedlings. The $1^{\text {st }}$, 2nd, 3rd and 4th instars larvae were used in bioassay.

\section{Bioassay and determination of different doses concentrations}

A leaf dip bioassay method was followed as described by Tabashnik, et al. (1991) using fully opened cabbage leaves. The leaves without the inside of the main plant from separate pots, were first washed with distilled water containing $\quad 0.1 \% \quad$ Triton X-100 thoroughly and dried. Leaf disc of $5 \pm 0.5$ $\mathrm{cm}$ diameter were cut from cabbage leaves and dipped in solutions of different concentrations prepared with $B$. thuringiensis. The tests of the Biturin $B$. turingiensis var kurstaki toxin product of Biotechnology Companies, mehr Asian (Mabko) in Iran (Semnan) in solution 3.6 percent of the materials were used effectively. Each disc was dipped for 10$15 \mathrm{~s}$. and allowed to air dry for a period of $1 \mathrm{~h}$. Then the discs were placed individually into small Petri dishes $(7 \mathrm{~cm}$ diameter). There were five concentrations ranging from 30 to 90 ppm for the1st instars, 50 to $140 \mathrm{ppm}$ for the 2nd instars, 90 to $200 \mathrm{ppm}$ for the 3rd instars and 150 to $250 \mathrm{ppm}$ for the 4th instars. Larvae were allowed to feed for $72 \mathrm{~h}$ at $25 \pm 2^{\circ} \mathrm{C}$ and more than $50 \% \mathrm{R}$. H. For toxicity bioassay experiment, $1^{\text {st }}, 2^{\text {nd }}$, $3^{\text {rd }}$ and 4th instars larvae were treated by oral application through cabbage leaf discs. Larval mortality was recorded up to $72 \mathrm{~h}$ of treatment. Because diamondback moth is such a sensitive insect to $B$. thuringiensis the $72 \mathrm{~h}$ mortality data observed were more efficient, and were strongly associated with results from longer bioassays.

\section{Data analysis}

Abbott's correction (Abbott, 1925) was applied to all data in the doseresponse experiments. Larvicidal activities of $B$. thuringiensis of the different crud extracts and fractions were statistically analyzed by general linear model (univariate) analysis of variance. The data were transformed by $\operatorname{Arcsin} \sqrt{ } \%$. Probit analyses were done to calculate median lethal concentration $\left(\mathrm{LC}_{50}\right)$ using SPSS 19 version software package.

\section{RESULTS}

In all four instars of the diamondback moth, effects of concentration and time were significant as was the interaction between concentrations and time. Mortality increased with increasing concentration and time in all instars. The susceptibility of the $1^{\text {st }}$ instar to $B$. thuringiensis were analyzed by leaf dip bioassay and mortality at 30, 39, 52, 68 and 90 ppm doses determined for 1st instar larvae at 24, 48 and $72 \mathrm{~h}$ after application is shown in Table 1 . In the $1^{\text {st }}$ instar the $\mathrm{LC}_{50}$ values at 48 and $72 \mathrm{~h}$ after treatment were very similar, at 0.994 and $0.822 \mathrm{ppm}$, respectively. Therefore, the $\mathrm{LC}_{50}(0.822 \mathrm{ppm})$ applied for $72 \mathrm{~h}$ were highest mortality concentration in our study. Using the formula $\omega^{2}$, the results for 1 st instar, $\omega^{2}=0.90$ for concentration, $\omega^{2}=0.064$ for time. 
Table 1.Toxicity of Bacillus thuringiensis to 1st instar Plutella xylostella

\begin{tabular}{clllllll}
\hline $\mathbf{L C}_{50}(\mathrm{ppm})$ & \multicolumn{2}{c}{$\mathbf{9 5 \%}$ Confidence limit } & Intercept & Slope \pm SE & $p$ & $X^{2}$ & Treated time (h) \\
& Lower & Upper & & & & & \\
\hline 0.587 & 1.393 & 2.372 & 0.814 & $3.513 \pm 0.372$ & 0.175 & 1.360 & 24 \\
0.455 & 0.994 & 1.413 & 1.397 & $4.080 \pm 0.387$ & 0.749 & 1.216 & 48 \\
0.385 & 0.822 & 1.116 & 1.774 & $4.283 \pm 0.416$ & 0.452 & 2.632 & 72 \\
\hline
\end{tabular}

The susceptibility of the 2nd instar to $B$. thuringiensis was analyzed by leaf dip bioassay and mortality at 50, 66, 85, 110 and $140 \mathrm{ppm}$ doses determined for $2^{\text {nd }}$ instar larvae at 24, 48 and $72 \mathrm{~h}$ after application is shown in Table 2. In the $2^{\text {nd }}$ instar the $\mathrm{LC}_{50}$ values at 48 and $72 \mathrm{~h}$ after treatment were very similar, at
0.688 and $0.593 \mathrm{ppm}$, respectively. Therefore, the $\mathrm{LC}_{50}(0.593 \mathrm{ppm})$ applied for $72 \mathrm{~h}$ were highest mortality concentration in this study. Using the formula $\omega^{2}$, the results for 2nd instar, $\omega^{2}=0.88$ for concentration, $\omega^{2}=0.077$ for time.

Table 2: Toxicity of Bacillus thuringiensis to $2^{\text {nd }}$ instar Plutella xylostella

\begin{tabular}{|c|c|c|c|c|c|c|c|}
\hline \multirow{2}{*}{$\mathrm{LC}_{50}(\mathrm{ppm})$} & \multicolumn{2}{|c|}{ \% Confidence limit } & \multirow{2}{*}{ Intercept } & \multirow{2}{*}{ Slope \pm SE } & \multirow{2}{*}{$p$} & \multirow{2}{*}{$X^{2}$} & \multirow{2}{*}{ Treated time (h) } \\
\hline & Lower & Upper & & & & & \\
\hline 1.003 & 2.129 & 3.385 & -0.005 & $4.027 \pm 0.411$ & 0.719 & 1.345 & 24 \\
\hline 0.688 & 1.306 & 2.793 & 0.601 & $3.756 \pm 0.403$ & 0.014 & 2.982 & 48 \\
\hline 0.593 & 1.018 & 2.085 & 0.838 & $3.692 \pm 0.419$ & 0.964 & 0.278 & 72 \\
\hline
\end{tabular}

Also sensitivity of $3^{\text {rd }}$ instar to $B$. thuringiensis at 90,110, 132, 162 and $200 \mathrm{ppm}$ doses determined for $3^{\text {rd }}$ instar larvae at 24, 48 and $72 \mathrm{~h}$ after application is shown in Table 3 . In the $3^{\text {rd }}$ instar the $\mathrm{LC}_{50}$ values at 48 and $72 \mathrm{~h}$ after treatment were different, at 1.219 and
$0.933 \mathrm{ppm}$, respectively. Therefore, the $\mathrm{LC}_{50}$ (0.933 ppm) applied for $72 \mathrm{~h}$ were highest mortality concentration in our study. Using the formula $\omega^{2}$, the results for 3rd instar, $\omega^{2}=0.90$ for concentration, $\omega^{2}=0.06$ for time.

Table 3: Toxicity of Bacillus thuringiensis to3rd instar Plutella xylostella

\begin{tabular}{cccccccc}
\hline LC $_{50}(\mathrm{ppm})$ & \multicolumn{2}{c}{ \% Confidence limit } & Intercept & Slope \pm SE & $p$ & $X^{2}$ & Treated time(h) \\
\cline { 2 - 8 } & \multicolumn{2}{c}{ Lower } & Upper & & & & \\
\hline 1.371 & 1.284 & 1.467 & -0.562 & $4.106 \pm 0.498$ & 0.802 & 0.998 & 24 \\
1.219 & 1.144 & 1.290 & -0.409 & $4.765 \pm .517$ & 0.870 & 0.714 & 48 \\
0.933 & 0.812 & 1.021 & 0.118 & $3.884 \pm 0.534$ & 0.767 & 1.142 & 72 \\
\hline
\end{tabular}

The susceptibility of the $4^{\text {th }}$ instar to B. thuringiensis was analyzed by leaf dip bioassay and mortality at 150, 170, 190, 220 and $250 \mathrm{ppm}$ doses determined for 4th instar larvae at 24, 48 and $72 \mathrm{~h}$ after application is shown in Table 4 . In the $4^{\text {th }}$ instar the $\mathrm{LC}_{50}$ values at 48 and $72 \mathrm{~h}$ after treatment were similar, at 1.952 and
$1.711 \mathrm{ppm}$, respectively. Therefore, the $\mathrm{LC}_{50}$ (1.711 ppm) applied for $72 \mathrm{~h}$ were highest mortality concentration in this study. Using the formula $\omega^{2}$, the results for $4^{\text {th }}$ instar, ${ }^{2}=0.89$ for concentration, $\omega^{2}=0.064$ for time.

Table 4: Toxicity of Bacillus thuringiensis to 4th instar Plutella xylostella

\begin{tabular}{|c|c|c|c|c|c|c|c|}
\hline \multirow[t]{2}{*}{$\mathrm{LC}_{50}(\mathrm{ppm})$} & \multicolumn{2}{|c|}{$\underline{95 \% \text { Confidence limit }}$} & \multirow[t]{2}{*}{ Intercept } & \multirow[t]{2}{*}{ Slope \pm SE } & \multirow[t]{2}{*}{$p$} & \multirow[t]{2}{*}{$\mathrm{X}^{2}$} & \multirow[t]{2}{*}{ Treated time (h) } \\
\hline & Lower & Upper & & & & & \\
\hline 2.204 & 3.195 & 4.123 & -2.745 & $7.998 \pm 0.838$ & 0.322 & 3.488 & 24 \\
\hline 1.952 & 3.015 & 3.926 & -2.040 & $7.023 \pm 0.783$ & 0.975 & 0.215 & 48 \\
\hline 1.711 & 2.646 & 3.270 & -1.697 & $7.278 \pm 0.813$ & 0.378 & 3.078 & 72 \\
\hline
\end{tabular}


The result shows that the instars larvae of Plutella xylostella to $B$. concentration factor was more important thuringiensis by leaf dip bioassay in than time in all four larval instars. different concentrations and times Comparison of mortality on the various (Table 5).

Table 5: Comparison of mortality on the various instars larvae of Plutella xylostella to Bacillus thuringiensis by leaf dip bioassay in different concentrations and times.

\begin{tabular}{|c|c|c|c|c|c|c|c|c|}
\hline \multirow{3}{*}{ Instar } & \multicolumn{4}{|c|}{ Comparing the average concentrations } & \multicolumn{3}{c|}{ Times are compared(h) } \\
\cline { 2 - 9 } & $\mathbf{1}$ & $\mathbf{2}$ & $\mathbf{3}$ & $\mathbf{4}$ & $\mathbf{5}$ & $\mathbf{2 4}$ & $\mathbf{4 8}$ & $\mathbf{7 2}$ \\
\hline $1^{\text {st }}$ & 29.432 & 36.432 & 50.623 & 58.545 & 66.572 & 34.343 & 41.952 & 47.932 \\
& \pm & \pm & \pm & \pm & \pm & \pm & \pm & \pm \\
& $0.567^{\mathrm{e}}$ & $0.634^{\mathrm{d}}$ & $0.430^{\mathrm{c}}$ & $0.467^{\mathrm{b}}$ & $0.726^{\mathrm{a}}$ & $0.241^{\mathrm{c}}$ & $0.715^{\mathrm{b}}$ & $0.820^{\mathrm{a}}$ \\
\hline $2^{\text {nd }}$ & 28.889 & 38.163 & 49.961 & 59.514 & 65.986 & 32.491 & 41.767 & 48.762 \\
& \pm & \pm & \pm & \pm & \pm & \pm & \pm & \pm \\
& $0.572^{\mathrm{e}}$ & $0.402^{\mathrm{d}}$ & $0.325^{\mathrm{c}}$ & $0.952^{\mathrm{b}}$ & $0.235^{\mathrm{a}}$ & $0.625^{\mathrm{c}}$ & $0.474^{\mathrm{b}}$ & $0.775^{\mathrm{a}}$ \\
\hline $3^{\text {rd }}$ & 33.789 & 42.737 & 50.624 & 58.545 & 66.572 & 36.887 & 41.440 & 48.761 \\
& \pm & \pm & \pm & \pm & \pm & \pm & \pm & \pm \\
& $0.522^{\mathrm{e}}$ & $0.525^{\mathrm{d}}$ & $0.464^{\mathrm{c}}$ & $0.148^{\mathrm{b}}$ & $0.490^{\mathrm{a}}$ & $0.628^{\mathrm{c}}$ & $0.439^{\mathrm{b}}$ & $0.525^{\mathrm{a}}$ \\
\hline $4^{\text {th }}$ & 25.309 & 34.231 & 44.75 & 55.177 & 60.614 & 29.278 & 37.095 & 44.624 \\
& \pm & \pm & $4 \pm$ & \pm & \pm & \pm & \pm & \pm \\
& $0.314^{\mathrm{c}}$ & $0.48258^{\mathrm{d}}$ & $0.699^{\mathrm{c}}$ & $0.835^{\mathrm{b}}$ & $0.601^{\mathrm{a}}$ & $0.314^{\mathrm{c}}$ & $0.489^{\mathrm{b}}$ & $0.350^{\mathrm{a}}$ \\
\hline
\end{tabular}

*Dissimilar letters indicate significant differences statistically significant at the 5 percent level by the Tukey test.

\section{DISCUSSION}

A recent survey of biopesticide researchers working in developing countries indicated that formulation was the most important issue in the development of biological insecticides (Harris and Dent, 2000). Microbial pesticides, particularly B. thuringiensis, are likely to become increasingly important as pest resistance and environmental concerns reduce the usefulness of conventional insecticides. Although laboratory selection has increased resistance to B.thuringiensis in several species of insects McGaughey, (1985); mcGaughey and Beeman, (1988); Stone, et al. (1989); Miller, et al. (1990). The results of experiments in this study show that concentrations of 90, 140, 200 and $250 \mathrm{ppm}$ on $1 \mathrm{st}, 2^{\text {nd }}, 3^{\text {rd }}$ and $4^{\text {th }}$ instars larvae provides the highest mortality base on intestinal activity of $B$. thuringiensis, respectively. The greatest casualty is being treated after 72 hours. The results of this study, in various instar larvae of this pest with Talekar and Griggs, (1986); Krieg and Langenbruch, (1981); Johnson et al., (1990) and Van Rie et al., (1990) is somewhat similar, test results, but different Mohan and
Ggjar, (2000) and Tang et al., (1997), that reason, not using this toxin is against this pest in Iran, Protection of crucifer crops from damage often requires application of insecticide to plant foliage, sometimes as frequently as twice per week. However, resistance to insecticides is widespread, and includes most classes of insecticides including some Bacillus thuringiensis products. Rotation of insecticide classes is recommended, and the use of $B$. thuringiensis is considered especially important because it favors survival of parasitoids. Even $B$. thuringiensis products should be rotated, and current recommendations generally suggest alternating the kurstaki and aizawa strains because resistance to these microbial insecticides occurs in some locations.

In summary, as in most cases, the best opportunity to manage resistance to $B$. thuringiensis in diamondback moth is to take action before resistance occurs. $B$. thuringiensis should be used judiciously to conserve its efficacy against diamondback moth. Management programs that emphasize biological and cultural controls can integrate $B$. thuringiensis and other insecticides 
sparingly, thereby prolonging their usefulness.

\section{ACKNOWLEDGEMENTS}

We thank Dr. Youbert Ghusta, Department Head, for comments and assistance in manuscript preparation and Yousef Shadeghoshchi and Ebrahim Hassanzadeh, Mehdi Razmi, Mohammad Ali Ghanbari for their assistance with the insect bioassays.

\section{REFERENCES}

Abbott WS (1925). A method of computing the effectiveness of an insecticide. J. Econ. Entomol., 18: 265-267.

Dunhawoor, C. and Abeeluck, D. (1998). Integrated control of Plutella xylostella (L.) Lepidoptera: Plutellidae) in Mauritius. P 181-187. In Lalouette JA and Bachraz DY. Eds. Proceedings Second Annual Meeting of Agricultural Scientists. 12-13 August 1997. Food and Agricultural Research Council. Reduit, Mauritius.

Flexner, J. L., Lighthard, B. and Croft, B. A. (1986). The effects of microbial pesticides on non-target, beneficial arthropods. Agriculture, Ecosystems and Environment. 3: 515-518.

Harris, J. and Dent, D. (2000). Priorities in Biopesticide Research and Development in Developing Countries. CABI Publishing, Walling-ford, UK.

Johnson, D. E.; Brookhart, G. L.; Kramer, K. J.; Barnett, B. D. and McGaughey, W. H. (1990). Resistance to Bacillus thuringiensis by the Indian meal moth, Plodia interpunctella: comparison of midgut proteinases from susceptible and resistant larvae. Journal of Invertebrate Pathology., 55: 235-244.

Krieg, A. and Langenbruch, G. A. (1981). Susceptibility of arthropod species to Bacillus thuringiensis. In Burgess, H. D. Microbial Control of pests and Diseases 1970-1980. Academic Press., New Yourk., 837840.

McGaughey, W. H. (1985). Insect resistance to the biological insecticide Bacillus thuringiensis. Science., 229: 193-195.

McGaughey, W. H. and Beeman, R. W. (1988). Resistance to Bacillus thuringiensis in colonies of Indian meal moth and almond moth (Lepidoptera: Pyralidae). Journal of Economic Entomology., 81: 28-33.

Miller, D. L., Rahardja, U. and Whalon, M. E. (1990). Developmnt of a strain of Colorado potato beetle resistant to the delta- endotoxin of Bacillus thuringiensis Pest Resistance Mnagement., 2: 25.

Mohan, M. and Gujar, G. T.(2000). Susceptibility pattern and development of resistance in the diamondback moth, Plutella xylostella L. to Bacillus thuringiensis Berl var Kurstaki in India. Pest Management Sci., 56: 189-194.

Nisin, K. D., Mo, J. and Miyata, T. (2000). Decreased susceptibilities of four field populations of the diamondback moth, Plutella xylostella (L.) (Lepidoptera: Plutellidae), to acetamiprid. Applied Entomology and Zoology., 35: 591595.

Runner, E. and Stevens, P. F. E. (1986). The control of diamondback moth with Thuricide. In Talekar, n. S. and Grigge, T. D. [ed.]. Diamondback Moth Mangement: proceedings of the first international workshop. Asian Vegetable Research and Development Center, Shanhua, Taiwan., 213-217pp.

Shelton, A. M., Sances, F. V., Hawley, J., Tang, J. D., Boune, D., Collins, H. L. and Farias, J. (2000). Assessment of insecticide resistance after the outbreak of diamondback moth (Lepidoptera: Plutellidae) in California in 1997. Journal of 
Economic Entomology., 93: 931936.

Stone, T. B., Sims, S. R. and Marrone, P. G. (1989). Selection of tobacco budworm for resistance to a genetically engineered Pseudomonas fluorescens containing the deltaendotoxin of Bacillus thuringiensis subsp. Kurstaki. Journal of Invertebrate Pathology., 53: 228-234.

Sun, c. N., Wu, T. K., Chen, J. S. and Lee, W. T. (1986). Insecticide resistance in diamondback moth. In Talekar, n. S. and Grigge, T. D. [ed.]. Diamondback Moth Mangement: proceedings of the first international workshop. Asian Vegetable Research and Development Center, Shanhua, Taiwan., 359-371 pp.

Talekar, N. S. and Shelton, A. M. (1993). Biology ecology and management of the Diamondback moth. Annual Review of Entomology., 38: 275-301. Talkar, N. S. and Griggs, T. D. (1986). Diamondback Moth Management: proceedings of the first international workshop. Asian Vegetable Research and Development Center, Shanhua, Taiwan., 471 pp.
Tang, J. D.; Gilboa, S.; Roush, R. T and Shelton, A. M. (1997). Inheritance stability and lack of fitness costs of field selsected resistance to Bacillus thuringiensis in diamondback moth (Lepidoptera: Plutellidae) from Florida. Journal of Economic Entomology., 90: 732-741.

Thiery, I. and Frachon, E. (1997). Identification, isolation, culture and preservation of enthomopathogenic bacteria, p. 55-73. In A. L. Lacey [ed.], Manual of Techniques in Insect Pathology, Academic Press, London. Van Rie, J.; McGaughey, W. H.; Johnson, D. E.; Barnett, B. D. and Van Mellaert. H. (1990). Mechanism of insect resistance to the microbial insecticide Bacillus thuringiensis. Science, 247: 72-74.

Wilcox, D. R.; Shivakumar, A. G.; Miller, M. F.; Benson, T. A.; Shopp, C. W.; Casuto, D.; Gundling, G. J.; Bolling, T. J.; Spear, B. B. and Fox, J. L. (1986). Genetic engineering of bioinsecticides. In Inouye, $M$. and Sarma, R. [ed.]. Protein Engineering: Applications in Science, Medicine and Industry. Orlando, Fla: Academic., 395-413 pp. 